\title{
Assessment of the life cycle of masonry walls in residential buildings
}

\author{
Jacek Korentz, and Beata Nowogońska* \\ University of Zielona Góra, Institute of Structural Engineering, Poland
}

\begin{abstract}
Environmental assessment over the course of the full life cycle of a building (LCA - Life Cycle Assessment) covers the environmental burden connected with energy consumption and the accompanying emission of contaminants into the atmosphere from the moment of obtaining a raw material and all stages of its processing and treatment, through the service life of a building, up to the moment that the use value of the building expires and the storage of waste. Literature on the subject is already very rich in this scope. There are numerous works pertaining to the guidelines for calculating all costs of the life cycle of buildings, i.e. environmental, economic and social costs. In these works, however, not much is said about the means of determining the life cycle of building structures. This is very important, especially in the case of the analysing the cycle of the further existence of buildings no longer in use, as well as newly designed ones. The article presents a method of predicting the performance characteristics of a building over the course of its use. The application of this method has been illustrated by the prediction of the performance characteristics of masonry walls, verified by studies carried out on existing buildings. The method - the purpose of research, can be applied to determine the life cycle (LC) of buildings for which LCCA (Life Cycle Cost Analysis) is carried out. A significant problem pertaining to every object in use is ensuring adequate reliability. The process of modeling reliability should have a mathematical basis enabling the problem to be described in detail. The ultimate aim is applying this description when solving problems connected with planning renovation work.
\end{abstract}

\section{Introduction}

Up until the end of the 80 s of the $20^{\text {th }}$ century, the costs of erecting buildings and operating costs were treated separately. Very little attention was paid to the operating costs of building structures [1]. The need to account for costs in the life cycle of buildings arose along with issues of environmental protection in the developing doctrine of sustainable development. Development which meets current needs while not jeopardizing the possibility of fulfilling the needs of future generations has led to the emergence of a new outlook on the issue of constructing buildings and stricter control in the processes of:

\footnotetext{
* Corresponding author: b.nowogonska@ib.uz.zgora.pl
} 
manufacturing materials, erecting and using building $[1,2,3]$.

Legal regulations regarding the issue of sustainable development have already appeared in Polish legislation. In accordance with the standards [4], three aspects of sustainable development are distinguished: 1) the environment - the thought-out use of the environment in a manner that does not lead to its degradation is a necessity 2 ) economics economic growth along with just division of the resultant benefits and 3) society - social issues, standard of living. The development of construction consists in introducing innovative technologies and modern solutions which combine environmental aspects, including the use of raw materials and energy efficiency alongside favourable economic effects, with social aspects.

Literature on the topic is very rich in this scope [1-5]. There are numerous works regarding the guidelines for calculating all costs of the life cycle of buildings, i.e. environmental, economic and social costs. However, not much is said about the means of estimating or determining the length of the life cycle of building structures. This is very important, especially in the case of analysing the cycle of the further existence of buildings no longer in use, as well as newly designed ones.

\section{Buildings and sustainable development}

Familiarity with the course of the life cycle of a building forms the basis for properly identifying the condition of the structure at each phase of its existence. In the concept of sustainable development, the analysis of the costs of the life cycle was connected, above all, with environmental protection. Over the recent years, the issue of the cost accounting of buildings in Life-Cycle Cost Analysis (LCCA) has been considered in terms of choosing the most beneficial variant accounting for environmental values [3]. Analyses of the economic efficiency of an investment are already carried out at the design stage, involving the verification of the hypothesis regarding the influence of design solutions on costs during the full life cycle of a building. The carried out studies show that, in the costs of the life cycle of a building (purchase costs $9 \%$, energy costs $46 \%$, others $10 \%$ ), maintenance and renovation works consume $35 \%$ of the total costs of a building [3]. Buildings are often characterized by a long service life, and thus flexible design tendencies, i.e. accounting for the possibility of later modernization, occur more and more frequently [6]. Solutions based only on a single design variant are not adapted to changes and requirements over the entire life-cycle of a building, and may, in this way, generate losses.

In accordance with the principles of sustainable development, the quality of execution is important, both over the course of constructing new buildings as well as during the renovation and modernization of existing ones. Quality influences the performance characteristics of buildings, the optimization of which relies on achieving a maximum level of serviceability while, at the same time, fulfilling the requirements of minimal energy usage as well as securing environmental balance [2]. During the life cycle of buildings, damage, failures and disasters should be monitored. An analysis of the reasons behind their occurrence leads to establishing which factors influence the states of building hazard and what design strategies ought to be chosen to ensure safety and conditions of use that meet the expectations of users.

\section{Service life of a building}

The service life of building structures depends on the physical and material wear processes of their components. The processes occurring in the individual elements of a building contribute to the technical wear of its structural and finishing elements, as well as the 
equipment and installations and, consequently, the technical wear of the entire building. The technical durability of buildings is determined as the ability to fulfil the requirements of a user under specified conditions for a given period of time, not resulting in the deterioration of the performance characteristics or excessive maintenance costs. The assessment of technical wear is not an easy process. The life cycles of individual building components set out in standards are useful for this purpose. They can range from a few years (paint coats) to a few dozen years (brick walls).

The set of PN-ISO standards "Planning service life" [7, 8] provides general guidelines regarding the issues of predicting the service life of a building structure. Determining changes in the performance characteristics of buildings requires the application of Predicted Service Life Distribution of the Component (PSLDC) risk curves, as support tools for planning the dates of renovation works. In accordance with recommendations set out in standards [7, 8], an assessment of the performance characteristics of a buildings ought to be carried out, and changes in these characteristic over time foreseen when developing methods that simulate the projected degradation of a good over time.

\section{Methods of determining and predicting performance characteristics}

The problem of ensuring an adequate level of the technical condition of a building occurs over the entire period it is in service. In solving problems connected with developing a prediction of changes in performance characteristics of a residential building, it is suggested that algorithms of determining changes in the reliability of technical devices be used. The prognosis of unfavourable processes will make it possible to determine the time frame in which the technical condition of a building will be unsatisfactory in the future, and thus necessitate repair works. A measure of the reliability of technical devices is the $R(t)$ function, also referred to as the survival function [e.g. 9].

For modelling situations in life cycle analysis, when the probability of failure changes over time, the Weibull distribution is used, as the distribution of the random variable of the time buildings are fit for use. This distribution belongs to the family of asymmetrical gamma distributions. The Weibull distribution has been widely applied for many years, as a distribution of durability and distribution of the time of the proper performance and life of the analysed goods [10].

The probability density function of the Weibull $\mathrm{f}(\mathrm{t})$ distribution is described by the relationship:

$$
f(t)=\alpha \beta^{\alpha} t^{\alpha-1} \exp \left(-(\beta t)^{\alpha}\right) \text { dla } t \in(0, T)
$$

where: $\mathrm{t}$ - service life of a building or component

$\mathrm{T}$ - standard life cycle of building or component,

$\alpha>0$ - scale parameter,

$\beta>0$ - shape parameter.

The distribution parameter $\alpha$ describes the maintenance of the probability of failure over time, while the $\beta$ parameter is a coefficient characterizing the speed at which reliability disappears.

The cumulative distribution function referred to as the probability of damage, a function of building unreliability or failure rate for the Weibull distribution is indicated by the formula:

$$
F(t)=\int f(t) d t=1-\exp (-\beta t)^{\alpha}
$$

The reliability function, also referred to as the probability of proper operation or 
survival function, is a change over time in the probability of non-damage with Weibull distribution density and is described by the formula:

$$
R(t)=1-\mathrm{F}(\mathrm{t})=\exp \left(-(\beta t)^{\alpha}\right)
$$

The intensity of damage $\lambda(\mathrm{t})$ can also be an indicator characterizing the reliability of a building. The course of the $\lambda(t)$ function depends on the physical properties of the building, the operating conditions and the assumed damage criteria. The intensity of damage is defined as the intensity of the probability of damage or the rate at which unreliability $F(t)$ increases in relation to reliability $\mathrm{R}(\mathrm{t})[9]$.

$$
\lambda(t)=\frac{d F(t)}{d t} \frac{1}{R(t)}=\alpha \beta^{\alpha} t^{\alpha-1}
$$

Based on the intensity of damage $\lambda(t)$ function, the degree of technical wear $S_{z}(t)$ can be determined, expressed by the formula:

$$
S_{z}=\int \lambda(t) d t=\beta^{\alpha} t^{\alpha}
$$

Figure 1 presents the course of changes in the performance characteristics of building components over time for various standard life cycles $\mathrm{T}$, described by the Weibull distribution according to Formula (3).

As can be noticed in Fig. 1, in the beginning period of the life cycle of an element the rate of changes in the performance characteristics of these elements is not very high; later the influence of time on the decline of performance characteristics is higher, and after exceeding a certain threshold of technical wear, the rate at which performance characteristics of building components decrease is, once again, lower. This, of course, is the result of the assumed probability distribution, in this case the Weibull distribution. However, as shown by comparisons of the results of research and results of calculations, the presented Weibull distribution reflects the course of changes in the performance value of masonry walls made of ceramic brick with adequate.

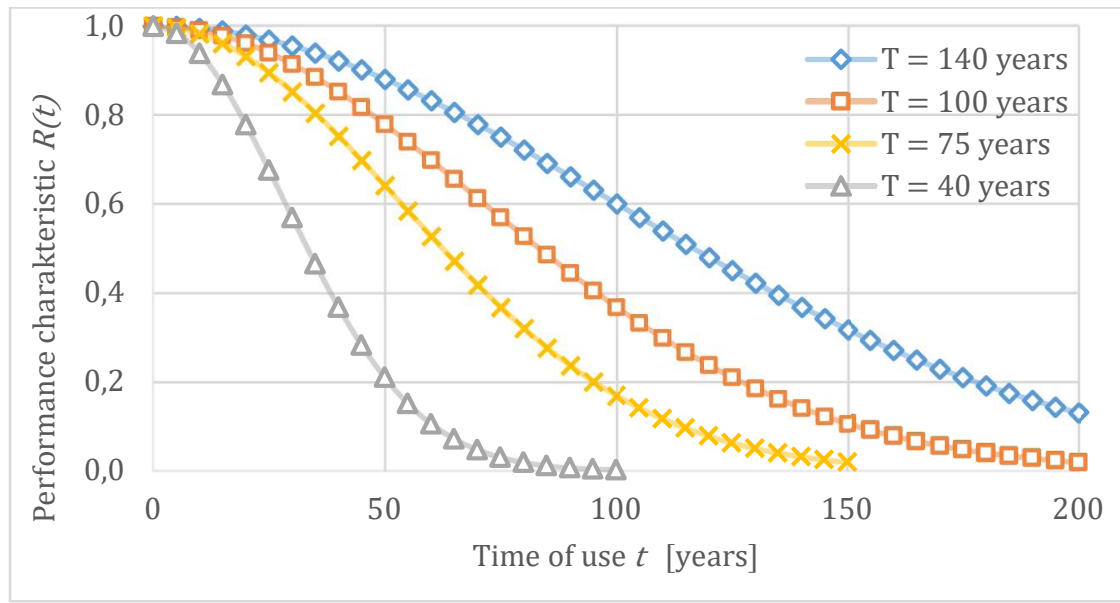

Fig. 1. Changes in the performance values of building components for various standard life cycles

A special case of the Weibull distribution, where the parameter of shape $\alpha=2$, is the Rayleigh distribution. This distribution is a single-parameter distribution and occurs when the wear of the component over time is the main reason for failure [10]. The decision to apply the Rayleigh distribution for buildings appears to be the most accurate. All buildings and their components undergo wear over the course of their use, and the Rayleigh 
distribution is applied in cases when the wear of the building or component increases along with the time it is in use.

Over the course of their use, building structures are subject to constant destructive processes which can take a various course. Over time, performance characteristics deteriorate, and can be partially returned as a result of repair works.

The PRRD (Prediction of Reliability according to Rayleigh Distribution) model of changes in the performance values proposed in work [11] is a description of the changes in the performance characteristics of a residential building over the its entire service life. This model may also be applied for predicting changes in the performance characteristics of individual building components. The model is based on the Rayleigh distribution, which is a specific case of the Weibull distribution for the scale parameter $\alpha=2$.

A forecast of changes in the performance characteristics of an element $R(t)$ in the PRRD model for the life cycle $T$ of an element is determined from Formula (3) for $\alpha=2$ and $\beta=1 / T$ and is expressed by the relationship:

$$
R(t)=\exp \left(-\left(\frac{t}{T}\right)^{2}\right)
$$

whereas the intensity of damage $\lambda(t)$ is described by the relationship:

$$
\lambda(t)=2 \frac{t}{T^{2}},
$$

and the degree of wear $\mathrm{S}_{\mathrm{z}}(\mathrm{t})$ in this model is equal to:

$$
S_{z}(\mathrm{t})=\left(\frac{t}{T}\right)^{2}
$$

Being familiar with the life cycles of buildings or building components set out by standards, we can carry out the prognostic analyses of changes in their performance characteristics. The accurate determination of the life cycle $T$ of buildings and their components is a very difficult task; thus, literature provides different standard life cycles, i.e.: average $\mathrm{T}_{\mathrm{avg}}$, minimum $\mathrm{T}_{\min }$, and maximum $\mathrm{T}_{\max }$.

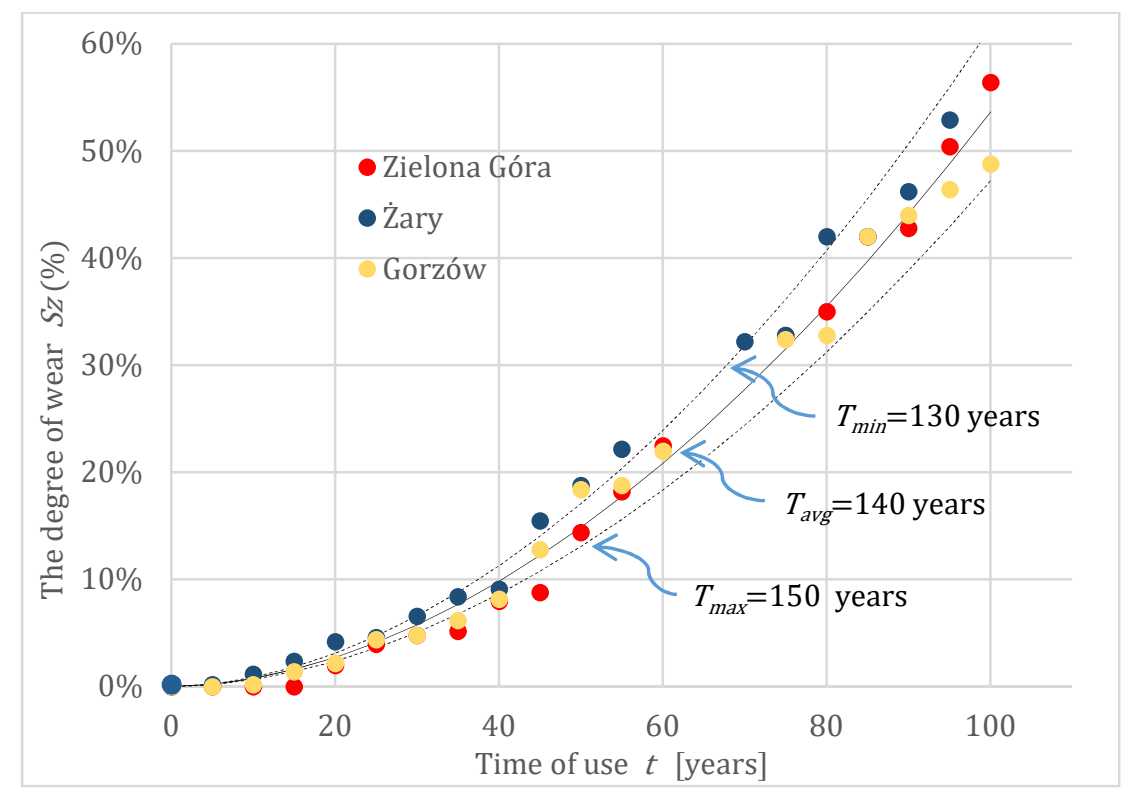

Fig. 2. Comparing the predictions of changes in the degree of wear of masonry walls with the results of periodical inspections of buildings located in Zielona Góra, Żary and Gorzów. 
The presented model of assessing the degradation of a building or its components over time (PRRD) was subjected to validation, making use of the results of periodical inspections of existing buildings in the area of Zielona Góra, Żary and Gorzów. These comprised residential buildings constructed using traditional technology, the periodical inspections of which have been carried out for a few dozen years. The subject of comparative analysis were the load-bearing walls of those buildings which were made of ceramic brick. As a rule for forecasting changes in the performance characteristics of walls over time, Relationship (8) was assumed, being a function of changes in the degree of technical wear over time. Changes in the degree of technical wear indicated for the minimum, average and maximum life cycle of masonry walls indicated by the standards were: 130, 140 and 150 years, respectively. Figure 2 shows a comparison of the results regarding the degree of technical wear of masonry walls determined during periodical inspections and the results of the forecasted technical wear of these walls calculated using the PRRD method. In the graph, good agreement between the predicted and actual degree of technical wear of masonry walls can be observed. Nearly all degree of technical wear determined during periodical inspections fall within the range of forecasted technical wear for the minimum $\mathrm{T}_{\min }$ and maximum $\mathrm{T}_{\max }$ standard life cycle of walls, while the function best describing technical wear is the function for the average standard life cycle $T_{\text {avg. }}$.

\section{Summary}

The life cycle of a building comprises three basic periods: investment, service and demolition. Accounting for all cost groups in the individual mentioned periods is possible thanks to carrying out Life Cycle Cost Analysis (LCCA).

Fig. 2 shows that, after the passing of 100 years, the degree of technical wear of masonry walls $S_{z}$ can range from $50 \%-60 \%$. The degree of technical wear of other building components will be higher or lower from that presented. The degree of technical wear depends on, above all, the standard life cycle of buildings or building components.

The presented analyses of the length of the life cycle of a given structural element - in this case masonry walls - may serve as the basis for more precise determination of the life cycle (LC) of buildings in LCCA analyses.

\section{References}

1. A. Dziadosz, M. Rejment, O. Kapliński, Total Costs of a Building in the Life Cycle of a Building Investment. Selected Problems of Construction [in Polish]. Wydawnictwo Uniwersytetu Technologiczno-Przyrodniczego w Bydgoszczy, s. 20-25, (2015)

2. L. Runkiewicz, Realization of Buildings Structures According to the Principles of Sustainable Development [in Polish]. Przegląd Budowlany No. 2/2010, pp. 17-23 (2010)

3. M. Piasecki, Sustainable Construction - Harmonization of Requirements and Methods of Assessment [in Polish] Materiały konferencyjne Międzynarodowej Konferencji Energetycznej + SET- Plan, Warszawa (2011)

4. PN-EN 15643-1: 2011 Sustainability of Building Structures. Assessment of Buildings) [in Polish]. Part 1. General Guidelines).

5. A. Leśniak, K. Zima, Comparison of traditional and ecological wall systems using the AHP method, International Multidisciplinary Scientific GeoConference 
Surveying Geology and Mining Ecology Management, SGEM, Albena, Bulgaria, 2015 3(5), pp. 157-164 (2015)

6. C. A. Arboleda, D. M. Abraham, Evaluation of Flexibility in Capital Investments of Infrastructure Systems. Engineering Construction and Architectural Management, 2006 13(3), pp. 254-274 (2006)

7. PN-ISO 7162:1999 Service Requirements in Construction. Content and Form of Standards Regarding the Assessment of Performance Characteristics) [in Polish]

8. PN-ISO 15686-2: 2005 Buildings and Structures. Planning Service Life. Part 2. Procedures Connected with Predicting Service Life) [in Polish]

9. S. Niziński, Elements of diagnostics of technical objects, Publisher of University of Warmia and Mazury in Olsztyn, Olsztyn (2001) [in Polish].

10. R. E. Walpole, R. Myers, Probability and Statistics for Engineers and Scientists. Macmillan Publishing Company, London (1985)

11. B. Nowogońska, Model of the reliability prediction of masonry walls, Engineering Mechanics 2014 - 20th international conference Svratka, Czechy. Brno University of Technology, s. $456-459$ (2014). 